\title{
DC Motor Control System with PID Controller
}

\author{
Aung Ye Tun \\ Department of Electrical \\ Systems and Instrumentation, \\ Myanmar Aerospace \\ Engineering University, \\ Meiktila Township, \\ Mandalay Division, Myanmar
}

\begin{abstract}
With the rapid development of DC motor and computer technology, the DC motor control system is widely used in many industrial fields especially in aeronautic and astronautic application. With the high response, good adaptability and flexibility, DC motor has precise and fine control performance and a wide adjustable speed range. The aim of this paper is to study the dynamic performance of DC motor control system and provide the corresponding control law so as to improve its dynamic performance. In this paper establishes the mathematical model of DC motor control system, investigates the PID control algorithm to reach the high performance of whole system. Utilizing the Matlab Simulink, the simulation results indicate that the system modeling and controller are content to the system requirement.
\end{abstract}

Keywords: DC motor, PID controller, system simulation

\section{INTRODUCTION}

In control or robotic engineering, motor control plays a major role and is an unavoidable part, regardless of whether it is speed or position control. The effectiveness of a controller can be justified by performance objectives such as for high precision or rapid movement. Like other trade-off schemes, some control architecture has advantages over the others under certain real-application situations.

\section{MODELLING OF DC MOTOR}

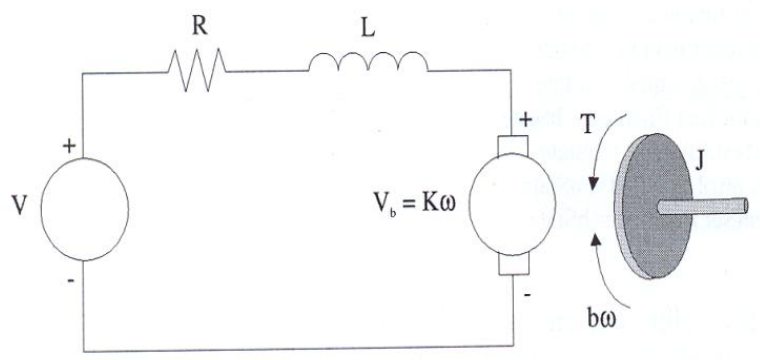

Figure 1. Electric circuit of the armature and the free body diagram of the rotor

The motor torque $T$ is relative to the armature current, $i$ by a constant factor $K$

$$
T=K i
$$

The back electromotive force (emf), $V_{b}$, is related to the angular velocity by;

$$
V_{b}=K \omega=K \frac{d \theta}{d t}
$$

Following equation is derived by using the Newton's law and Kirchhoff's law

$$
\begin{gathered}
J \frac{d^{2} \theta}{d t^{2}}+b \frac{d \theta}{d t}=K i \\
L \frac{d i}{d t}+R i=V-K \frac{d \theta}{d t}
\end{gathered}
$$

Using the laplace transform equation (3) and (4)

$$
\begin{aligned}
& (J s+b) s \theta(s)=K I(s) \\
& I(s)=\frac{V(s)-K s \theta(s)}{(L s+R)}
\end{aligned}
$$

According to Equation (5) and (6)

$$
G_{a}(s)=\frac{\theta(s)}{V(s)}=\frac{K}{s\left[(J s+b)(L s+R)+K^{2}\right]}
$$

$$
G_{v}(s)=\frac{\omega(s)}{V(s)}=\frac{K}{(J s+b)(L s+R)+K^{2}}
$$

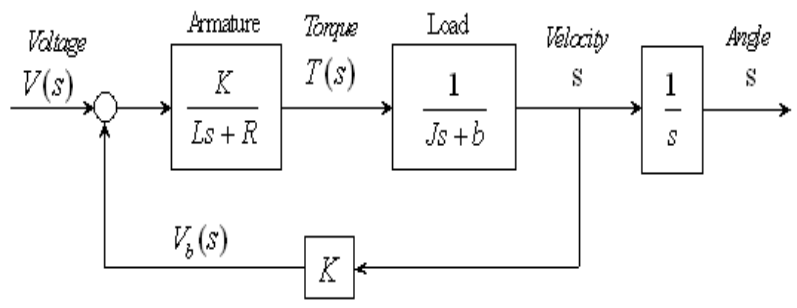

Figure 2. Block diagram of the DC motor 
The DC motor parameters shown as follows.

Table 1. DC motor parameter

\begin{tabular}{|c|c|c|}
\hline Symbol & Name & parameter \\
\hline $\mathrm{J}$ & Inertia & $0.01 \mathrm{Kg}-\mathrm{m}^{2} ?$ \\
\hline $\mathrm{L}$ & Inductance & $0.5 \mathrm{H}$ \\
\hline $\mathrm{R}$ & Resistance & $1 \mathrm{ohm}$ \\
\hline $\mathrm{B}$ & Damping coefficient & $0.1 \quad \mathrm{~N}-\mathrm{m}-\mathrm{sec} / \mathrm{rad}$ \\
\hline$K_{m}$ & motor Constant & $0.01 \mathrm{~N}-\mathrm{m} / \mathrm{A}$ \\
\hline$K_{B}$ & Back-EMF Constant & $0.01 \mathrm{~V}-\mathrm{sec} / \mathrm{rad}$ \\
\hline
\end{tabular}

\section{PID CONTROLLER}

The traditional expressions for PI and PID controllers can be described by their transfer functions, relating error $\mathrm{E}(s)=\mathrm{R}$ $(s)-\mathrm{Y}(s)$ and controller output $\mathrm{U}(s)$.

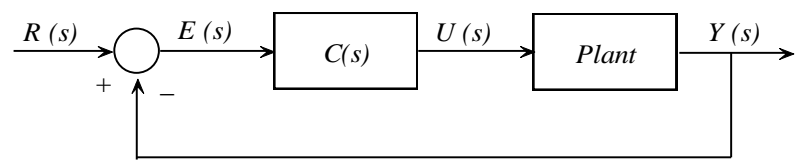

Figure 3. basic feedback control loop

For control over steady state and transient errors all the control strategies discussed so far should be combined to get proportional -integral-derivative (PID) control. Here the control signal is a linear combination of the error, the time integral of the error, and the time rate of change of the error. All three gain constants are adjustable.

The PID controller contains all three control components (proportional, derivative, and integral). Its transfer function model can be derived as follows:

$U(y)=K_{P} e(t)+K_{d} \frac{d e(t)}{d t}+K_{i} \int_{0}^{t} e(t) d t$

\section{SIMULATION OF DC MOTOR}

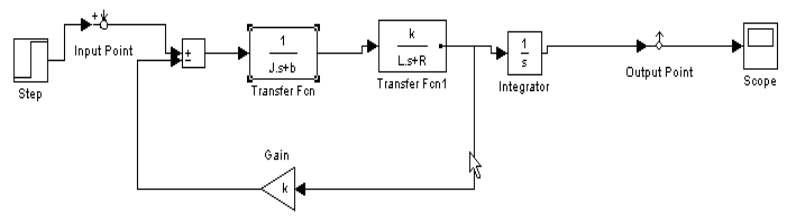

Figure 4.Simulink diagram of DC motor

According to figure 5, for time domain, response time is greater than 2.5 second. The system should get response time is less than 0.1 second for good response. So the system has to combine with PID controller to reduce the response time.

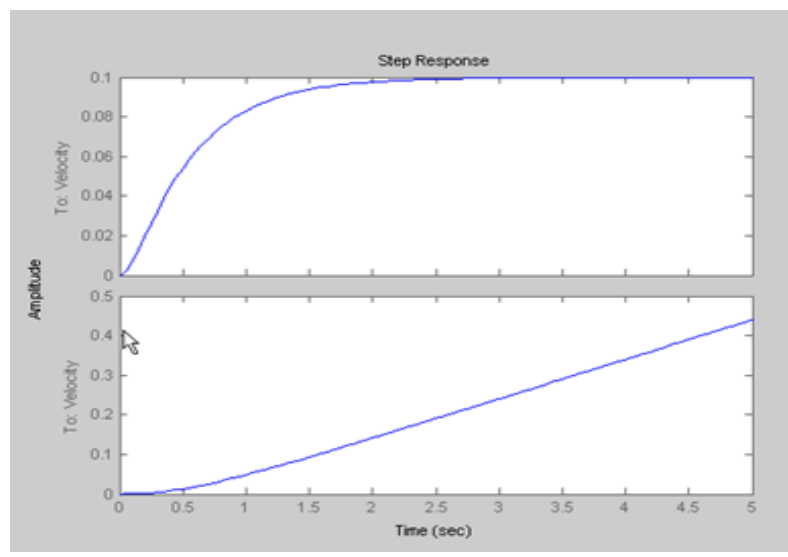

Figure 5. Step Response of DC motor

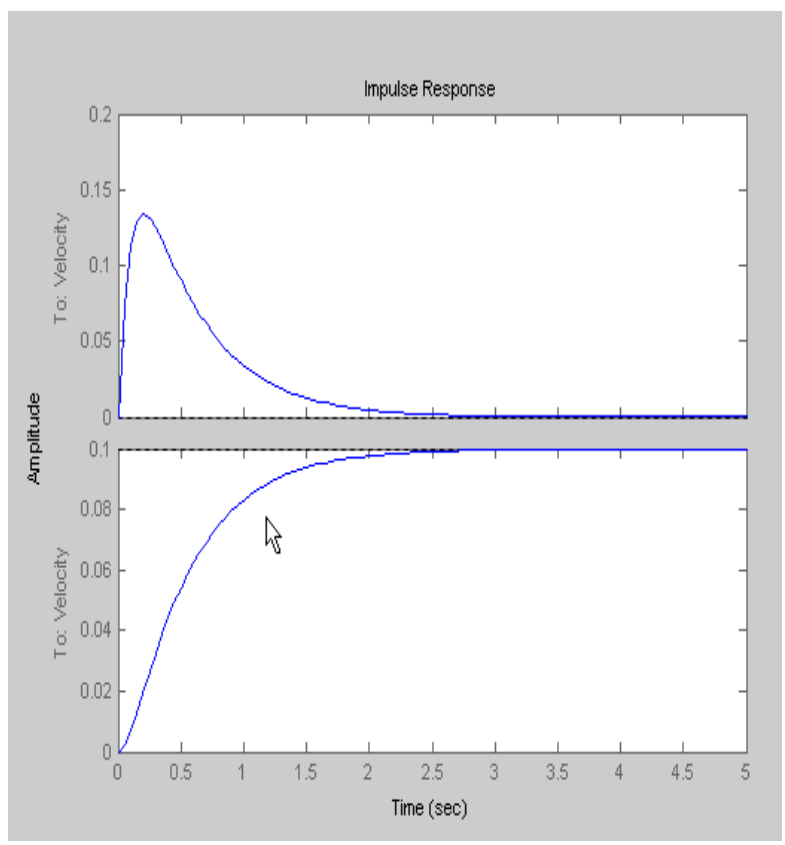

Figure 6. Impulse Response of DC motor

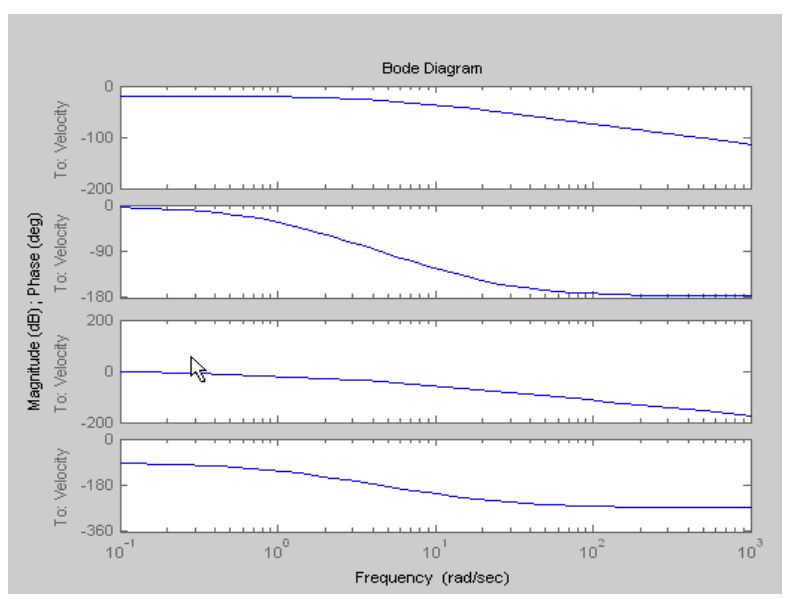

Figure 7. Bode diagram of DC motor 


\section{SIMULATION WITH PID CONTRO-}

\section{LLER}

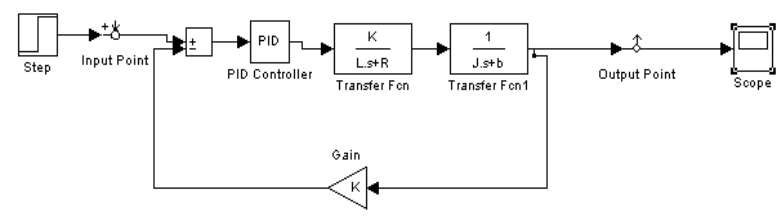

Figure8. simulink diagram of system

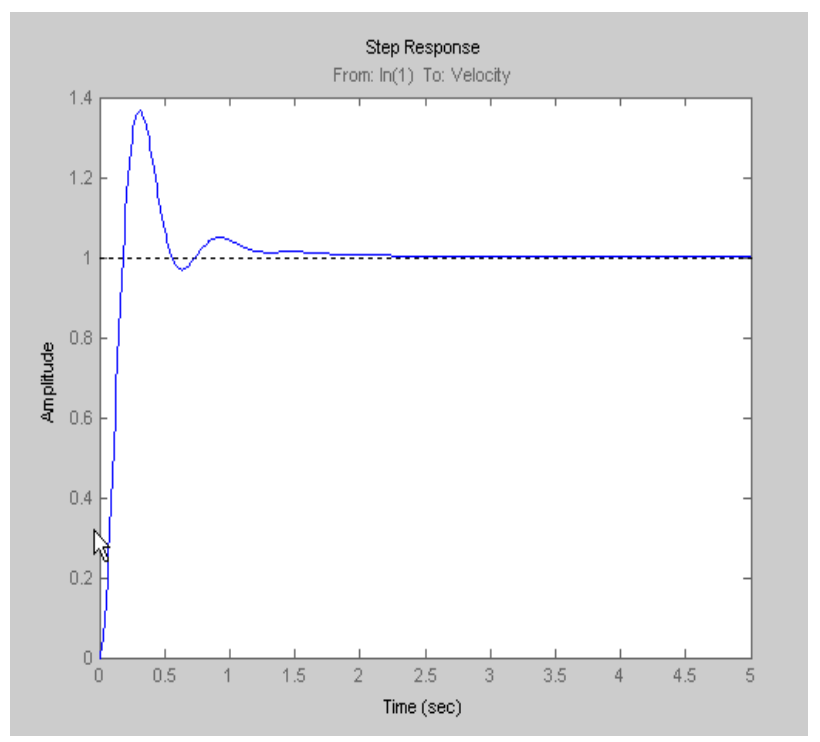

Figure 9. Close-loop step response with PID controller

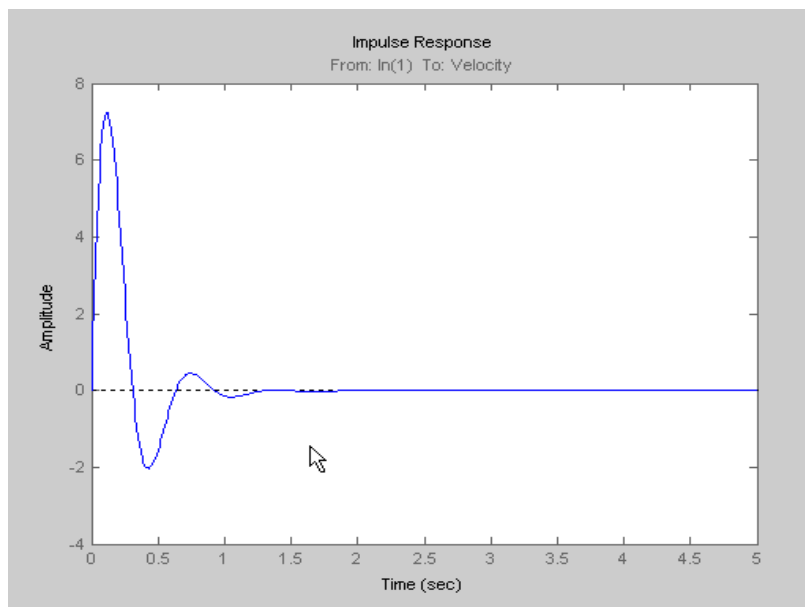

Figure 10. Close-loop impulse response with PID controller

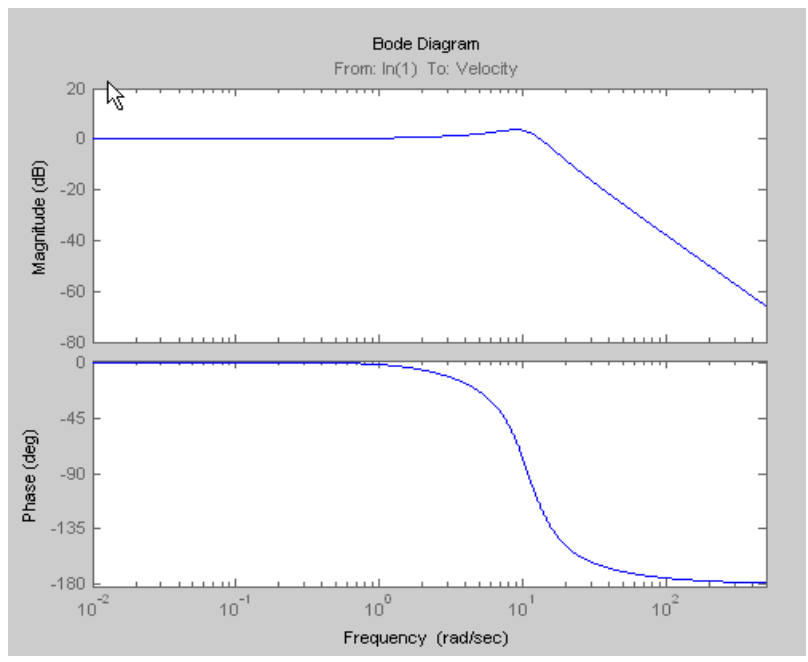

Figure 11. Close-loop bode diagram with PID controller

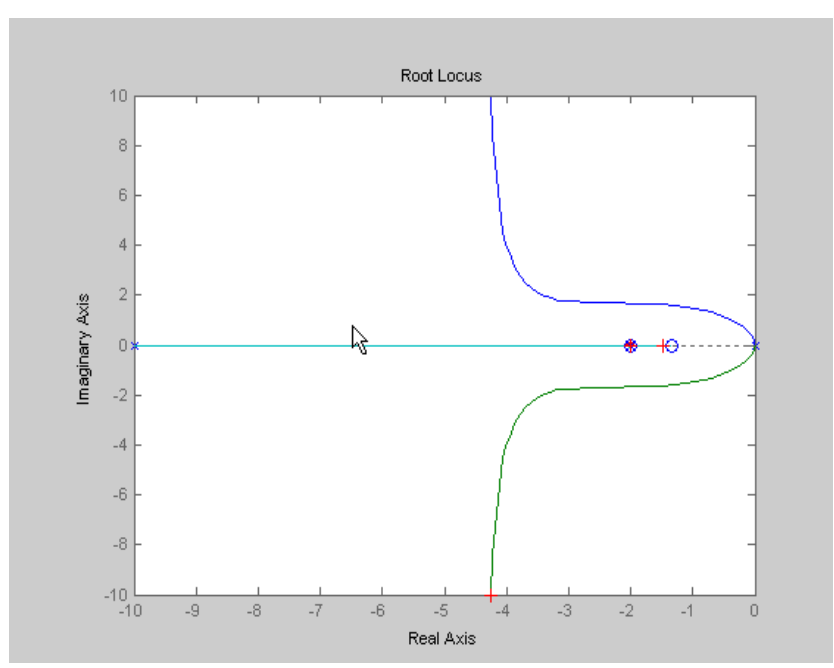

Selected point $-9.8223+9.0994 i$

Figure 12. Root Locus diagram of PID controller

PID eliminates overshoot and decrease the rise time. To improve the settling time we try first to decrease $\mathrm{Kd}$.

\section{CONCLUSION}

In this paper, basic technique for improvement by doing analysis and design of DC motor control system with PID controller is discussed. Therefore, we will learn how to develop a linear model for a DC motor, how to analyze the model under matlab (poles and zeros, frequency response, time-domain response, etc.), how to design a controller, and how to simulate the open-loop and closed-loop systems under simulink.

In my paper, DC motor system is modeled by summing torque acting on the inertia and integrating the acceleration to give the velocity, Kirchoff's Law is applied to the armature circuit and simulation for control system are discussed.

Simulation is today a very important part of engineering design. A lot of simulation software is available today for engineers. 
In simulating the DC motor and controller is deriving its equations of motions. The second step is finding the transfer function. To get the transfer function, we have to apply the laplace transform.

PID controller is discussed in detail. We can determine the parameter of controller according to their response.

In the case of feed forward control, the system has no loop. So that the controller will measure the new torque (by measuring the current) and will increase or decrease the voltage. So, in feed forward control, the controller will not affect the system stability because there is no loop. So we must be use close loop system.

In paper program by using matlab for DC motor control system are discussed. The program enables the analysis of the control system in time and frequency domains, and also makes it possible to optimise the parameters of the control systems.

\section{REFERENCES}

[1] Encyclopedia Brittanica, "Electricity and Magnetism," Macropedia, Vol. 18, pp. 193-194,1995.

[2] T.C. Martin and J. Wetzler, "The Electric Motor and its Applications", book, W.J. Johnston,Publisher, 1887.

[3] Nikolai Tesla, "A New System of Alternate Current Motors and Transformers," AIEE Transactions, 1888.

[4] A. Blondel, "Synchronous motor and converter, Part III," book, McGraw-Hill, New York,1913.

[5] R.H. Park, "Two reaction theory of synchronous machines- Part I," AIEE Transactions, Vol. 48, No. 2, 1929, pp.716-730.

[6] F. Blaschke, "The principle of field orientation as applied to the new Transvektor closed-loop control system for rotating field machines," Siemens Review XXXIX, 1972, pp. 217-220.

[7] Limei Wang and Robert D. Lorenz, 'Permanent Magnet Synchronous Motor Using Saliency-Tracking SelfSensing Method'.

[8] Todd D. Batzel and Kwang Y. Lee, ' Motor Slotless Permanent Magnet Synchronous Operation without a High Resolution Rotor Angle Sensor'

[9] Hyung-Tae Moon, Hyun-Soo Kim, and Myung-Joong Youn, 'A Discrete-Time Predictive Current Control for PMSM'

[10] Mo-Yuen Chow, Senior Member,IEEE and Yodyium Tipsuwan,Student Member, IEEE, 'Gain Adaptation of Networked DC motor Controllers Based on QOSVariations'

[11] Chen , Analog and Digital Control System,S college Publishing, NY,1993

[12] Li Yunhua, Shi Wei Xiang, an Introduction to Artificial Intelligent Control,BUAA, Beijing China 1998.

[13] Earl Cox, the Fuzzy System Hand Book,ISBN AP Professional,1998

[14] Bishop,R.,Modern Control Systems Analysis and Design using Matlab and Simulink, Addsion Wesley Longman Inc, 1997.
[15] J. F. Lindsay and M.H.Rashid' 'Electromechanics and Electrical Machinery' 